\title{
Um olhar realista maravilhoso a partir d'A varanda de frangipani
}

\section{A wonderful realistic view from A varanda de frangipani}

\author{
Luciana Helena Cajas Mazzutti \\ INARA RODRIGUES \\ Universidade Estadual de Santa Cruz - Ilhéus - Bahia - Brasil
}

Resumo: A análise de $A$ varanda do frangipani (2007), de Mia Couto, permite, por meio de discussões implicadas nos estudos pós-coloniais, destacar especificidades político-sociais relacionadas à identidade, tradição e cultura. As personagens coutianas problematizam, na narrativa, sentidos identitários e o processo de independência de Moçambique, seguido dos traumáticos desdobramentos da guerra civil pela disputa do poder. No romance, a tradição, ou "antigamente", parece silenciada, contudo, Couto aponta para um possível resgate dessas vivências ao frisar ritos, crenças e práticas. O escritor moçambicano marca a pluralidade cultural e, desse modo, elabora uma tessitura realista maravilhosa. Nessa perspectiva, valemo-nos dos estudos voltados ao Realismo Maravilhoso, que enfatiza eventos insólitos e elementos culturais vinculados ao espaço-tempo, à linguagem e ao discurso sociocultural.

Palavras-chave: Identidade; Insólito; Mia Couto; Realismo Maravilhoso

\begin{abstract}
The analysis of $A$ varanda do frangipani (2007), Mia Couto, through discussions focused on Post-colonial studies, allows us highlighting social and political specificities related to identity, tradition and culture. Characters by Couto may deepen in the narrative, identity senses and the Independence process in Mozambique, followed by the traumatic consequences of the civil war, because of the dispute of power. In the novel, tradition or "old times" seems silenced, however, Couto points to a possible rescue of those experiences to emphasize rites, beliefs and practices. The Mozambican writer marks the cultural plurality and thus prepares a wonderful realistic texture. In this perspective, we use the studies aimed at focusing the Magical Realism, emphasizing unusual events and cultural elements related to space-time, language and socio-cultural discourse.
\end{abstract}

Keywords: Identity; Unusual; Mia Couto; Magical Realism

A narrativa coutiana $A$ varanda de frangipani (2007) gira em torno do assassinato que ocorre no asilo de São Nicolau, uma antiga fortaleza colonial. O narrador, Ermelindo Mucanga, um xipoco - fantasma -, retorna ao mundo dos vivos no corpo do inspetor de polícia Izidine Naíta com a missão de descobrir quem matou o diretor do asilo, Vasto Excelêncio.

O romance está dividido em quinze capítulos, dos quais seis referem-se ao ocorrido no asilo; são confissões/ versões; os outros capítulos, pode-se dizer, referem-se à busca da "verdade". Izidine Naíta, responsável pela investigação, tem dificuldade em desvendar o crime já que todos se declaram culpados. Os interrogados contam como mataram o diretor e o motivo pelo qual merecia morrer, as declarações são convincentes e, ao mesmo tempo, descabidas - na concepção do inspetor policial confundindo, ainda mais, a investigação.

Cada uma das confissões apresenta um aspecto importante que colabora para interpretar sentidos identitários e o processo de independência de Moçambique, seguido dos traumáticos desdobramentos da guerra civil pela disputa do poder. Assim, esta análise de $A$ varanda do frangipani tem como objetivos, por meio de discussões implicadas nos estudos pós-coloniais, destacar e problematizar questões relacionadas à cultura, à identidade e à tradição no âmbito da literatura moçambicana contemporânea.

Nesse sentido, no terceiro capítulo, por exemplo, em que se apresenta a primeira confissão, Navaia Caetano, um dos idosos que vive no asilo, descreve um ritual ao 
qual foi submetido para que não morresse, já que sofria de um 'mal' adquirido no nascimento. $\mathrm{O}$ diretor do asilo, um negro moçambicano que assume tal condição de poder, desfaz do rito e na tentativa de afastar/silenciar a tradição, questiona:

- Que merda é esta? Que se passa aqui? [Reclama o diretor]

Nossa cerimónia [de Navaia Caetano e os outros idosos] era bruscamente interrompida por Vasto Excelêncio. O director abusou de boca, sujou-nos o nome.

- Eu não disse que estão proibidas estas macacadas no asilo?

Os outros velhos explicaram: aquela cerimónia era para me salvar a mim. O mulato me olhou, espantado. Se aproximou do meu leito como se se quisesse certificar da minha identidade. Quando seus olhos se fixaram nos meus foi como se um golpe o derrubasse. Sacudiu a cabeça, esfregou as pálpebras a esborratar a visão. Depois, virou-me costas e proclamou:

- Ou me arrumam já esta merda ou pego fogo a tudo, bebidas, velhos, crianças, tudo. (COUTO, 2007, p. 36, grifo nosso)

Vasto Excelêncio, não aceita mais a tradição, usa da violência para tentar silenciá-la. Denomina o ritual de "macacada". Mas, por um momento, o diretor perde sua suposta superioridade ao fixar o olhar no homem submetido ao ritual e se reconhece nessa pratica, como se fosse resgatado dessa cegueira "civilizatória". No entanto, ao esfregar as pálpebras, retorna à realidade, à hierarquia, ao poder adquirido. Essa situação exemplifica o que Albert Memmi observou sobre o sujeito que, “[...] socialmente oprimido por alguém mais poderoso que ele, encontra sempre um outro menos poderoso que possa oprimir, fazendo-se assim, por sua vez, tirano" (2007, p. 50). O colonizado passa a reproduzir o comportamento do colonizador e a hierarquia estabelecida na colônia, resultando em um jogo explícito de poder que envolve perdas e ganhos.

Por outra perspectiva, o romance apresenta imbricamentos que constituem os intercâmbios culturais. No quinto capítulo, Domingos Mourão, português Xidimingo como foi batizado pelos idosos -, conta sua história e também assume ter matado o diretor. Quando se refere ao seu apelido, o velho português afirma que "[...] ganhei afecto desse rebaptismo: um nome assim evita canseira de me lembrar de mim" (COUTO, 2007, p. 45). Desse modo, pode-se aproximar Mourão da figura do desertor, ainda conforme proposição de Memmi: “[...] para conseguir se tornar um desertor, ao que ele enfim se decidiu, não basta aceitar totalmente aqueles pelos quais deseja ser adotado, é preciso ainda ser adotado por eles" (2007, p. 73). O batizado sublinha a aceitação por parte dos ex-colonizados e reafirma a condição do português/ ex-colonizador de desertor.

Esses diferentes posicionamentos entre colonizador $\mathrm{x}$ colonizado configuram a complexidade das relações estabelecidas no processo de colonização que se refletem nos contextos pós-coloniais. Se, de um lado, temos o diretor negro e nascido em Moçambique que nega sua origem ao reproduzir práticas autoritárias; por outro, temos Mourão, português branco, na tentativa de uma condição igualitária após a descolonização, o que, nesse último caso, assinala certa impossibilidade, já que, no romance em estudo, evidenciam-se as relações assimétricas e racistas que se reproduzem no microcosmo social do asilo.

Uma passagem exemplar, nesse último sentido, encontra-se no nono capítulo, em que Nãozinha, a feiticeira, conversa com o velho português e Nhonhoso - o pequeno ancião - quando, de repente, são chamados ao gabinete do diretor. Nhonhoso não cumpriu a ordem de Vasto Excelêncio para derrubar o frangipani, planta que simboliza, na narrativa coutiana, a relação entre o homem, filho da terra moçambicana, e o divino, o sonho, a transcendência. $\mathrm{O}$ fato de recusar-se a destruir esse símbolo, desobedecendo o diretor, implica em ser castigado:

Então, Excelêncio se virou para Nhonhoso e gritou:

- Mandei-lhe cortar a árvore do tuga e você desobedeceu. Agora já sabe...

- Eu sei. Mas estou a pedir uma coisa: não chame ninguém para me bater.

Depois, virando-se para o velho português, Nhonhoso implorou:

- Por favor, você me bata.

- Bater-te!? Estás doido?

- Eu não quero que seja um preto a me bater.

- Não me peça isso, Nhonhoso. Eu não posso, não sou capaz.

Nesse momento, o director interrompeu. Perguntou ao branco, com o maior sarcasmo:

- Não diga que você nunca arreou num preto. Heim, patrão?

Sublinhava bem a palavra "patrão". Nhonhoso, para nossa surpresa, juntou voz a Excelêncio:

- Sim, me satisfaça esse pedido, patrão.

- Não entendo, Nhonhoso: agora eu sou 'patrão'? (COUTO, 2007, p. 83)

Percebe-se, nesse excerto, as contraditórias posições relacionais dos sujeitos submetidos à tirania exercida pelo diretor da instituição. No papel de algoz, Excelêncio não recua em seu gesto violento e autoritário, reproduzindo a força dos signatários do ex-poder colonial. Entretanto, Nhonhoso pede para não ser castigado por um homem negro, forçando o reposicionamento do diretor, negro 
como ele; para isso, pede que esse papel de verdugo seja exercido por um homem branco, demarcando a situação do português do asilo. O propósito de Nhonhoso não cumpre seu efeito, porém: Vasco Excelêncio, sarcástico, sente-se superior ao velho lusitano e parece demonstrar quem, agora, afinal é o "patrão". O efeito de redimensionamento crítico de papeis, contudo, realiza-se no processo de leitura e demonstra, vivamente, a complexidade das relações identitárias na realidade contemporânea de Moçambique.

Outra questão relevante no romance refere-se à situação de Izidine Naíta, o policial: ao sair da sua terra para estudar na Europa e ser um homem de gabinete, ele passa a negar sua origem. $\mathrm{O}$ inspetor não é cruel com os moradores do asilo, mas não se reconhece mais como nativo, passando a vivenciar o que o Grupo Moderidad/ Colonialidad denomina de "a colonialidade do saber", ou seja, quando o único conhecimento válido, reconhecido, é o que se desenvolve nas "metrópoles", nos centros de poder europeus e norte-americanos. Entretanto, Marta, a enfermeira da instituição, adverte o inspetor:

- Está a ver a sua arrogância? Pois fique sabendo que, todas as manhãs, o morto grita o nome do assassino.

- Não posso crer.

- Todas as manhãs o morto clama juras de vingança. Agora, sentado junto à rebentação das ondas, o inspector lembrava as palavras da enfermeira. E sorria. Quem sabe Marta tinha razão? Ele estudara na Europa, regressara a Moçambique anos depois da Independência. Esse afastamento limitava o seu conhecimento da cultura, das línguas, das pequenas coisas que figuram a alma de um povo. Em Moçambique ele ingressara logo em trabalho de gabinete. O seu quotidiano reduzia-se a uma pequena porção de Maputo. Pouco mais que isso. No campo, não passava de um estranho. (COUTO, 2007, p. 41)

A aquisição de conhecimento nos grandes centros desvincula o policial da realidade cultural moçambicana, fazendo com que não se reconheça mais como "nativo". Esse não reconhecimento se amplia em relação a suas vivências com o interior rural de Moçambique, onde se mantém mais vivas as tradições dos diferentes povos que compõem a paisagem culturalmente multifacetada do país. Assim, não é só o colonizador que cala/nega a cultura local, o próprio nativo nega a tradição. Couto (2007) busca com narrativa resgatar "o antigamente", mas antes demonstra a desvalorização pela qual passa a tradição moçambicana:

O mundo, lá fora, tinha mudado. Já ninguém respeitava os velhos. Dentro e fora dos asilos era a mesma coisa. [...] De fora vinham familiares e soldados roubar comida. Os velhos que, antes, ansiavam por companhia já não queriam receber visitantes.
- Sofremos a guerra, haveremos de sofrer a Paz.

Salufo explicava-se assim: em todo o mundo, os familiares trazem lembranças para reconfortar os que estão nos asilos. Na nossa terra era ao contrário. [...] Todos se haviam convertido em cabritos. E como diz o ditado cabrito come onde está amarrado. (COUTO, 2007, p. 107)

Assim como Vasto Inocêncio, conforme citado anteriormente, muitos foram "cegados" pela disputa do poder do país agora independente. Salufo não suporta ver os maus tratos para com os idosos, a prática desumana do diretor. Esse descaso não expressa só o desrespeito para com os idosos moradores do asilo, mas, principalmente, a tradição negligenciada, distanciada e silenciada. Explique-se que, por tradição, não se faz aqui referência a nenhuma "pureza" essencial da cultura moçambicana. O que se demarca são traços de resistência cultural, de sentidos de identificação locais, de explicadores comportamentais e valorativos, sempre reconstruídos de geração a geração, que são continuamente desafiados pela racionalidade eurocêntrica, alavancada como parâmetro civilizatório.

$\mathrm{Na}$ tentativa de proteger esse microcosmo que representa o que restou dos "antigamente" o capataz retorna a São Nicolau e toma uma atitude drástica:

[...] [começa] a minar as terras em redor da fortaleza. Enterraria as mesmas minas que, lá na estrada, estavam a ser retiradas.

- Eles estão a desminar. Eu vou começar a minar.

$[\ldots]$

- Mas, você, Salufo...

- Agora é que isto vai ser uma fortaleza de verdade!

- Estás maluco, Salufo?

- Não, senhora. Eles é que estão doidos.

- Mas para quê? Minar porquê, Salufo?

- Eu vi esse mundo. Não quero que ninguém venha aqui nos chatear. (COUTO, 2007, p. 108)

Para Salufo, minar os arredores da fortaleza é uma forma de preservar a tradição, a cultura, as crenças, os costumes praticados pelos "antigamente". Couto (2007) retrata a miséria e o esquecimento que o asilo de São Nicolau enfrenta. No capítulo décimo primeiro, a viúva de Vasto Excelêncio deixa uma carta revelando o motivo para matar o marido e descreve a condição do asilo; já no décimo terceiro, Marta, a enfermeira narra sua versão e expõe a falta de medicamentos, o descaso com os idosos por parte dos governantes e do diretor. Os trechos, respectivos aos capítulos mencionados, retratam a escassez vivida no asilo que é representativo do país independente:

Quando cheguei ao asilo confirmei as imoralidades de meu marido. Excelêncio negociava com os produtos 
destinados a abastecer o asilo. Os velhos não tinham acesso aos alimentos básicos e definhavam sem remédio. às vezes me parecia que morriam espetados em seus próprios ossos. Mas Vasto era insensível àquele sofrimento. (COUTO, 2007, p. 102)

Pedi a Excelêncio que mandasse vir novo recheio para reinstalar o centro sanitário em meu próprio quarto. Nessa altura, já tinha deixado de dormir sob aquele tecto. Mas os helicópteros militares que iam e vinham não tinham disponibilidade. Havia outras prioridades, me respondia Vasto Excelêncio. (COUTO, 2007, p. 123)

Entretanto, deve-se salientar que toda essa tessitura histórica que compõe os fios contextualizadores da narrativa é apresentada em meio a especificidades culturais do interior moçambicano, configuradas a partir de uma das categorias do Insólito: o Realismo Maravilhoso. Propõe-se, então, uma reflexão a partir das marcas culturais presentes na trama romanesca que a configura como produção literária caracterizada por uma das categorias do Insólito: o Realismo Maravilhoso. Segundo, Flavio Garcia (2013, p. 21),

falar em literaturas africanas de língua portuguesa, dentre elas a moçambicana, e, em particular, a de Mia Couto, equivale a falar de literatura pós-coloniais que, como veículo de afirmação de expressão identitárias nacionais, não buscam, em razão do processo colonizador, obviamente por motivações políticas conscientes ou não -, seus modelos nas metrópoles europeias - Portugal e Espanha, por exemplo -, senão que em ex-colônias cuja literatura nacional, refletindo o imaginário autóctone, houvesse se firmado mundo a fora - Brasil e demais países da América Latina [...].

Para Garcia (2013, p. 21), constata-se a proximidade da literatura moçambicana com a produção literária latino-americana. Caracteriza-se, assim, uma modalidade narrativa baseada na cultura própria desse espaço realmaravilhoso e "não real-naturalista" (GARCIA, 2013, p. 21). Para tanto, faz-se necessário recorrer ao Real Maravilhoso $^{1}$, termo cunhado por Alejo Carpentier (1968), e estabelecer a relação do discurso cultural, da tradição e do imaginário constituído a partir de uma experiência axiológica do sujeito inserido num determinado tempo/espaço com a produção narrativa: o Realismo Maravilhoso.

\footnotetext{
Segundo Alejo Carpentier (1987, p. 125) o real maravilhoso refere-se "a certos fatos que aconteceram na América, a certas características da paisagem, a certos elementos que têm alimentado" (:123) a sua produção literária; e afirma "o real maravilhoso, que eu defendo, e que é o nosso rela maravilhoso, é aquele que encontramos em estado bruto, latente, onipresente em tudo o que é latino-americano. Aqui o insólito é cotidiano, sempre foi cotidiano".
}

Segundo o estudioso haitiano, Louis Phillipe Dalambert (2013), é através da diversidade cultural que o Real Maravilhoso se faz presente não só na sua conceituação, mas, principalmente, na elaboração de uma produção narrativa própria do romance latino-americano. O Real Maravilhoso embasa o Realismo Maravilhoso; contudo, não são sinônimos, estão relacionados à cultura, contudo, o primeiro está diretamente ligado às práticas culturais; já o segundo designa uma modalidade narrativa presente na literatura. É relevante destacar o que distingue as modalidades insólitas e desvincular ambiguidades que se concretizam no que se refere ao Realismo Maravilhoso, Realismo Mágico e Fantástico.

Alguns estudos apontam para a utilização do termo Realismo Mágico a fim de "catalogar” a produção literária latino-americana, entretanto, Irlemar Chiampi (1980) descarta-o categoricamente, visto que, torna-se muito abrangente no que diz respeito à modalidade discursiva presente no romance da América Latina, além de ser formado por termos antagônicos que sugerem ideias opostas. Segundo Chiampi (1980, p. 19):

Realismo Mágico veio a ser um achado críticointerpretativo, que cobria, de um golpe, a complexidade temática (que era realista de um outro modo) do novo romance e a necessidade de explicar a passagem da estética realista-naturalista para a nova visão ('mágica') da realidade.

Em seu estudo $O$ realismo maravilhoso (1980), a professora constata que o termo Realismo Maravilhoso define de forma mais clara e precisa a narrativa latinoamericana, imbuída de mitos e tradições pertencentes ao cerne cultural. A essa modalidade discursiva, são atribuídas circunstâncias e motivações extrínsecas e intrínsecas nas quais o sujeito está inserido e não gera qualquer inquietação sobre a credibilidade dos eventos, o insólito é assimilado naturalmente.

Segundo Chiampi, "no Realismo Maravilhoso, o objetivo de problematizar os códigos sócio-cognitivos do leitor, sem instalar o paradoxo, manifesta-se nas referências frequentes à religiosidade, enquanto modalidade cultural capaz de responder à sua aspiração de verdade suprarracional" (1980, p. 63). Roland Barthes (1980) afirma que a tessitura narrativa expõe o "maravilhoso" como elemento que mascara, de certa forma, o que é real, racional, infraestrutural, funcionando como uma "cortina de arabescos" que retira o leitor da hesitação: "Do irreal ao real, haveria redução crítica, movimento alético, científico, como se o real fosse ao mesmo tempo magro e mais essencial do que as superstições com que o encobrimos" (1980, p. 91).

Tomando como base o leitor do Realismo Maravilhoso, constata-se a experiência axiológica do receptor 
perante a narrativa, pois "supera certas limitações e condicionamentos impostos pelo antagonismo entre o real e o irreal" (CHIAMPI, 1980, p. 67). O leitor convive com os elementos e os eventos apresentados no romance, contribui com a interpretação, além de acrescentar sua vivência social e cultural à assimilação da narrativa produzida por uma modalidade discursiva realista maravilhosa que pertence a seu universo.

Dessa forma, diferentemente do que ocorre no Fantástico e no Realismo Mágico, o Realismo Maravilhoso

propõe um 'reconhecimento inquietante', pois o papel da mitologia, das crenças religiosas, da magia e das tradições populares consiste em trazer de volta o 'Heimliche', ${ }^{2}$ o familiar coletivo, oculto e dissimulado pela repressão da racionalidade. [...] o realismo maravilhoso visa tocar a sensibilidade do leitor como ser da coletividade, como membro de uma (desejável) comunidade sem valores unitários e hierarquizados. (CHIAMPI, 1980, p. 69)

O estranhamento está presente no Realismo Maravilhoso, mas não assusta o leitor, ele é inserido no evento insólito, que por sua vez é estanho e conhecido; o receptor percebe o "oculto" como se estivesse sempre ali, presente, "escondido", ou seja, lhe é familiar. Segundo Antonio R. Esteves e Eurídice Figueiredo (2010), "a ideia não é exibir o Realismo Maravilhoso como o melhor, mas, simplesmente, como diferente, pela simples razão de que vem da maior e mais complexa mestiçagem do mundo" (2010, p. 402). Os autores não assinalam somente a diversidade de etnias; consideram, principalmente, que o mais importante e que se destaca no Realismo Maravilhoso é a diversidade pluricultural presente na vida e na produção literária latino-americana.

Nesse sentido, a cultura assinalada na narrativa coutiana em estudo caracteriza o Real Maravilhoso e, por sua vez, a modalidade narrativa: o Realismo Maravilhoso. Em $A$ varanda de frangipani, a oralidade, um aspecto cultural e tradicional, revela que o registro escrito é "desprezado" pelos antigos já que, de certa forma, impossibilita que reinventem ou reinterpretem as experiências vivenciadas. Os rituais regidos pela feiticeira Nãozinha, não causam hesitação; essas práticas ressignificam a tradição silenciada. $\mathrm{O}$ estranhamento se estabelece, porém, os sujeitos inseridos nesse contexto contribuem com o extranatural. Pode-se verificar como o evento insólito é referenciado na narrativa realista maravilhosa de Couto (2007). Segundo a personagem Navaia Caetano o seu "mal" fora adquirido antes do nascimento:

Quando ela [a mãe de Navaia Caetano] paria um novo menino, desaparecia o anterior filho. Mas todos esses que se sucediam eram idênticos, gotas rivalizando a mesma água. A gente da aldeia suspeitava de castigo, uma desobediência às leis dos antigos. Qual a razão desse castigo? Ninguém falava, mas a origem do mal todos conheciam: meu pai visitava muito o corpo de minha mãe. Ele não tinha paciências para esperar durante o tempo que minha mãe aleitava. É ordem da tradição: o corpo da mulher fica intocável nos primeiros leites. Meu velho desobedecia. Ele mesmo anunciou como superar o impedimento. Levaria para os namoros um cordão abençoado. Quando se preparasse para trebeliscar a esposa ele amarraria um nó na cintura da criança. $\mathrm{O}$ namoro poderia então acontecer sem consequências. Resolvia-se, na aparência, o adoentado destino de minha mãe. Digo bem, na aparência. Porque começou aí minha desgraça. Agora sei: nasci de um desses nós mal atados na cintura de um falecido irmão. (COUTO, 2007, p. 27)

A crença moçambicana remete à manutenção dessa tradição e nesse contexto elabora a realidade cultural. Navaia Caetano, o menino velho, explana a "maldição" contraída pelo fato do pai dele não ter respeitado o resguardo da mãe. Isso fez dele um menino que envelhecera em apenas um dia e para não morrer ele não pode, nunca, contar totalmente a verdade.

Assim, a função textual da narrativa realista maravilhosa se estabelece no "efeito de encantamento" suposto na função do leitor perante a função do narrador/personagem e que está presente na significação discursiva atribuída à obra literária. É necessário que se admita dois níveis operacionais, segundo Chiampi, "o do relato e o do discurso - pode-se desdobrar a atividade do narrador em duas instâncias diferenciadas: como foco narrativo ou como voz"3 (CHIAMPI, 1980, p. 71). Essas duas instâncias podem ser relacionadas ao que o narrador vê ou à forma como fala e/ou descreve os eventos.

Chiampi aponta um traço importante do Realismo Maravilhoso no plano da enunciação: a importância da renovação da linguagem ficcional presente na produção constituída na voz do narrador e na relação em que se estabelece com o narratário, pois:

\footnotetext{
2 Unheimlich (estranho, sinistro) deu título a um famoso ensaio de Freud de 1919: "O estranho". "Um dos sentidos de unheimlich, como o próprio Freud destacou, é justamente o de unbehaglish (o que provoca mal-estar). Se de certo modo podemos dizer que a psicanálise procedeu à revelação do Unheimlich da psique do indivíduo, ou seja, revelou 'tudo aquilo que deveria ter permanecido em segredo e oculto e veio à luz' (na definição do filósofo idealista Schelling, aprovada por Freud), no caso deste ensaio de 1930 Freud procura mostrar o oculto, o segredo, por detrás de toda cultura e da nossa humanidade, ou seja, seu malestar e suas origens mais profundas" (SELIGMANN-SILVA, 2010, p. 25) Logo, heimlich é tudo aquilo que permanece secreto, oculto, pertencente à casa, familiar, doméstico, íntimo, algo escondido, secreto, oculto.

3 Grifos da autora.
} 
a função do narrador constitui a sua performance como voz, através do questionamento da sua performance como foco. Pode-se dizer, sem risco de exagero, que a renovação da linguagem ficcional hispano-americana tem como eixo a problematização da perspectiva narrativa e a consequente crítica do próprio ato de contar. (CHIAMPI, 1980, p. 72, grifo da autora)

Conforme Chiampi (1980), o discurso presente no Realismo Maravilhoso se dá por meio de dois critérios: o da representatividade - "a capacidade de expressar um espaço cultural, uma sociedade, uma problemática histórica, com uma perspectiva não documental, mas integradora de várias faces do real" (CHIAMPI, 1980, p. 135) - e o da experimentação - "prática de técnicas narrativas audazes ou renovadoras com relação ao envelhecimento instrumental do realismo-naturalismo" (CHIAMPI, 1980, p. 135). A varanda de frangipani (2007) enquadra-se no primeiro critério, já que o asilo representa Moçambique a partir de um espaço cultural em que se destacam os conflitos de uma sociedade impregnada de crenças e mitos.

O romance não é um documento histórico, mas evidencia a problemática histórica na qual Ermelindo Mucanga - o xipoco - integra a realidade descrita pelo narrador/personagem e a condição social a que é submetido. A personagem entrega-se ao conforto de suas vontades e suas conclusões, mas logo é trazida à realidade, já que transita pelo mundo dos viventes. Nesse sentido, os comportamentos são determinados pela feiticeira do asilo a fim de remontar a tradição.

Ao aceitar-se esse último ponto, pode-se entender que a proposta do romance não é descobrir o culpado pelo crime; mas, através de Izidine Naíta, trata-se de recuperar o discurso identitário baseado em uma tradição cultural. Essa tradição, como já evidenciado, não tem qualquer sentido essencialista, mas aponta para uma identidade ressignificada e atravessada pela diversidade pluricultural.

Segundo o aporte teórico utilizado para este estudo, pode-se enfatizar o quanto são significativos os elementos culturais hibridamente formadores de um povo na elaboração de sua literatura. No romance em análise, as descrições destacam, na figuração das personagens, a metamorfose social, cultural e religiosa, provocada pelos desarranjos temporais e causais. Em $A$ varanda de frangipani, o discurso moçambicano pluricultural está marcado não só nos sujeitos sociais, mas, principalmente, na produção literária, nesse caso, evidenciado na narrativa coutiana realista maravilhosa.

\section{Referências}

CARPENTIER, Alejo. El reino de este mundo. Montevideo: Arca, 1968.

CARPENTIER, Alejo. O barroco e o real-maravilhoso. Do real maravilhoso americano. A literatura do maravilhoso. São Paulo: Vértice, 1987, p. 109-129, p. 130-142.

CASTRO-GÓMEZ, Santiago; GROSFOGUEL, Ramon. Prólogo. Giro decolonial, teoría crítica y pensamiento heterárquico. El giro decolonial: reflexiones para uma diversidad epistêmica más allá del capitalismo global. Bogotá: Siglo del Hombre, 2007. p. 9-24.

CHIAMPI, Irlemar. O realismo maravilhoso. São Paulo: Perspectiva, 1980.

COUTO, Mia. A varanda de frangipani. São Paulo: Companhia das Letras, 2007.

DALEMBERT, Louis Philippe. Espaços do imaginário latinoamericano: o real maravilhoso de Alejo Carpentier. Tradução de André Mitidieri e Rodrigo dos Santos Mota. In: SILVA, Denise Almeida (Org.). Poéticas do espaço, geografias simbólicas. Frederico Westphalen: URI, 2013. p. 61-76.

ESTEVES, Antonio Roberto; FIGUEIREDO, Eurídice. O realismo mágico e o realismo maravilhoso. In: FIGUEIREDO, Eurídice (Org.). Conceitos de literatura e cultura. Juiz de Fora, EdUFJF, 2010. p. 393-414.

FANON, Frantz. Os condenados da terra. Rio de Janeiro: Civilização Brasileira, 1968.

GARCIA, Flavio. Traços identitários da realidade moçambicana sob as lentes do Maravilhos. Apropriação de estratégias de construção narrativa real-maravilhosa em $A$ varanda de frangipani. In: GARCIA, Flavio. Discursos fantásticos de Mia Couto. Rio de Janeiro: Dilogarts, 2013, p. 21-24, 45-65.

MEMMI, Albert. Retrato do colonizado precedido do Retrato do colonizador. Rio de Janeiro: Civilização Brasileira, 2007.

SELIGMANN-SILVA, Márcio. Prefácio: a cultura ou a sublime guerra entre Amor e Morte. In: FREUD, Sigmund. O mal-estar na cultura. Tradução de Renato Seligmann-Silva. Porto Alegre: L\&PM, 2010, p. 21-38.

TODOROV, Tzvetan. Introdução à literatura fantástica. Trad. Maria Clara Correa Castello. São Paulo: Perspectiva, 1975.

SAID, Edward W. Cultura e imperialismo. Trad. Denise Bottmann. São Paulo: Companhia das Letras, 2011.

Recebido: 30 de abril de 2015 Aprovado: 28 de agosto de 2015 Contato: shanbarros@gmail.com 